\title{
Reciproc vs. hand instrumentation in dental practice: A study in routine care
}

Andreas Bartols, Claudius A Reutter, Bernt-Peter Robra, Winfried Walther

Background. Little is known about the clinical impact of new root canal preparation systems in general dental practice under routine care conditions. Therefore we compared hand instrumentation (H) with Reciproc (R) (VDW, Munich, Germany) preparation. The outcomes were endodontic related pain and oral health related quality of life (OHRQoL), evaluation of the procedures by the patients and the strain felt by the dentists during root canal therapy. Methods. Six dentists participated in the trial as practitioner-investigators. In the first phase of the trial they prepared root canals with $\mathrm{H}$ and in the second phase with $R$. The patients documented their pain felt with a visual analogue scale (VAS 100) and OHRQoL with the german short version of the oral health impact profile (OHIP-G-14) before treatment and before the completion of therapy and answered questions about how they experienced the treatment. The dentists documented their physical strain during treatment. Results. 137 patients were included in the evaluation. 66 patients were treated with $\mathrm{H}, 71$ with R. Pain reduction was 32.6 (SD 32.9) VAS (H) vs. 29.4 (SD 26.9) VAS (R) $(p=0.550)$, and the improvement of the OHIP-14 score was 5.5 (SD 9.2) (H) vs. 6.7 (SD 7.4) (R) $(p=0.383)$. There were no statistical differences in both groups. Significantly fewer patients felt stressed by the duration of treatment with $R$ as with $H(p=0.018)$. Significantly more dentists reported that their general physical strain and the strain on their fingers were less severe with $R$ than with $H(p=0.013$ and $p<0.001)$. Discussion. $H$ as well as $R$ effectively reduced endodontic related pain and OHRQoL without statistical differences. $\mathrm{R}$ has advantages in terms of how patients experience the treatment and regarding the physical strain felt by the dentists. 
1 Reciproc vs. hand instrumentation in dental practice: A study in routine care 2

3 Dr. Andreas Bartols, MA ${ }^{1,2}$, Dr. Claudius Reutter, MA ${ }^{3}$, Prof. Dr. Bernt-Peter Robra ${ }^{4}$, MPH, 4 Prof. Dr. Winfried Walther ${ }^{1}$

5

61 Dental Academy for Continuing Professional Development, Karlsruhe, Germany

72 School for Dental Medicine, Christian-Albrechts-University Kiel, Clinic for Conservative

8 Dentistry and Periodontology, Kiel

93 Private Practice, Alumni of Dental Academy for Continuing Professional Development,

10 Karlsruhe, Germany

114 Institute of Social Medicine and Health Economics, University of Magdeburg, Magdeburg,

12 Germany

13

14

Corresponding Author: Dr. A. Bartols, Dental Academy for Continuing Professional

Development, Lorenzstraße 7, 76135 Karlsruhe, Germany

17

andreas_bartols@azfk.de

Phone 00497219181101

19

Running head: Reciproc vs. hand instrumentation 


\section{Abstract}

22 Background. Little is known about the clinical impact of new root canal preparation systems in general dental practice under routine care conditions. Therefore we compared hand instrumentation (H) with Reciproc (R) (VDW, Munich, Germany) preparation. The outcomes were endodontic related pain and oral health related quality of life (OHRQoL), evaluation of the procedures by the patients and the strain felt by the dentists during root canal therapy.

Methods. Six dentists participated in the trial as practitioner-investigators. In the first phase of the trial they prepared root canals with $\mathrm{H}$ and in the second phase with $\mathrm{R}$. The patients documented their pain felt with a visual analogue scale (VAS 100) and OHRQoL with the german short version of the oral health impact profile (OHIP-G-14) before treatment and before the completion of therapy and answered questions about how they experienced the treatment. The dentists documented their physical strain during treatment.

Results. 137 patients were included in the evaluation. 66 patients were treated with $\mathrm{H}, 71$ with R. Pain reduction was 32.6 (SD 32.9) VAS (H) vs. 29.4 (SD 26.9) VAS (R) (p=0.550), and the improvement of the OHIP-14 score was 5.5 (SD 9.2) (H) vs. 6.7 (SD 7.4) (R) ( $p=0.383$ ). There were no statistical differences in both groups. Significantly fewer patients felt stressed by the duration of treatment with $\mathrm{R}$ as with $\mathrm{H}(\mathrm{p}=0.018)$. Significantly more dentists reported that their general physical strain and the strain on their fingers were less severe with $\mathrm{R}$ than with $\mathrm{H}$ $(\mathrm{p}=0.013$ and $\mathrm{p}<0.001)$.

Discussion. $\mathrm{H}$ as well as $\mathrm{R}$ effectively reduced endodontic related pain and OHRQoL without statistical differences. $\mathrm{R}$ has advantages in terms of how patients experience the treatment and regarding the physical strain felt by the dentists. 
43

44

\section{Introduction}

There is a wide selection of instruments for root canal preparation (Hargreaves et al. 2011). Whereas clinical data are available for hand instruments and rotary root canal preparation systems (Fleming et al. 2010), we know little about the impact in general dental practice under routine care conditions when the newest single-file systems are used.

In 2008 Yared was the first one to describe the preparation of root canals using only one instrument with reciprocating motion (Yared 2008). The further development of this concept led to the introduction of the Reciproc System (VDW, Munich, Germany), but also other reciprocating instrument systems as WaveOne (Dentsply, Konstanz, Germany), Genius files (Ultradent, South Jordan, UT, USA) or the Twisted Files Adaptive System (Kerr, Orange, CA, USA) with a combination of rotary and reciprocating movement. Besides reducing the number of instruments to one, Reciproc files are currently the only instruments that were also intended to allow root canal preparation without glidepath preparation (Yared 2011), while all other above mentioned systems were not primarily designed for this purpose. In-vitro studies prove that mechanical root canal preparation systems are superior to hand instrumentation in relation to various parameters, such as root canal straightening, preparation faults and preparation time (Kumar et al. 2013; Schäfer \& Florek 2003). The effectiveness gap between in-vitro studies and clinical reality in general dental practice, if any, is unknown. Therefore, our objective was to examine the effects of the new instruments under heterogeneous conditions of everyday life of different general dental practices. This goal requires a simplified pragmatic approach.

For the patients it is most important to eliminate endodontic related discomfort and to provide a comfortable treatment experience. Root canal therapy (RCT) is a common and effective treatment for the relief of endodontic-related pain (Pak \& White 2011). Whether there are any differences in effectiveness between hand instrumentation and Reciproc preparation has not been investigated so far. Moreover, there are no studies to the knowledge of the authors on whether patients consider different instrument systems more agreeable (or disagreeable) than others so that their experience differs during treatment. Another dimension rarely taken into account is the physical strain to which the dentist is exposed when using different methods of preparation under general dental practice conditions. 
72 This is why research is needed in the field of new endodontic instruments. For the purpose of

73 such research, we formed a network of several dental practices and performed a multicenter trial

74 (Patsopoulos 2011). For our trial we investigated processes of dental care under everyday

75 circumstances and on patient-relevant outcomes (Pfaff et al. 2011).

76 The following two-sided hypotheses were investigated in the study:

77 Does root canal preparation using Reciproc lead to more or less reduction of patients' endodontic

78 related pain and oral health related quality of life (OHRQoL) compared to using hand

79 instruments?

80 Do patients feel the Reciproc preparation to be more or less comfortable compared to hand

81 instrumentation?

82 Can the more root canals be prepared without glidepath preparation with Reciproc compared to

83 hand instrumentation?

84 Is the physical strain on the GDP during root canal preparation with Reciproc lower compared to 85 hand instruments?

86

\section{Methods}

We conducted the present study as a clinical multicenter trial under routine care conditions. The study involved nine dentists as practitioner investigators (P-Is). They recruited a sample of consecutive patients who needed a root canal treatment. The two phases of the study were separated by the training period for the new treatment method. The authors of this study did not act as P-Is, but solely as investigators.

In the first study phase endodontic therapy was performed in the usual way with hand instruments. The P-Is consecutively included all patients in the study who required endodontic therapy. Then the P-Is were trained for the use of the Reciproc System (VDW, Munich, Germany). The one-day training course explained the theoretical bases of the Reciproc System (VDW, Munich, Germany) for root canal preparation and included hands-on training on extracted teeth. At the end of the training course every participating dentist was technically able to prepare root canals by the new method in a reliable way. The training period was short on purpose because we wanted to simulate a common situation of changing treatment methods in general dental practice regarding the timeline sequence. 
101 In this way we calibrated the investigators and reduced the organizational demands on the dental

102 offices, because they did not have to perform two different methods of treatment at the same 103 time.

104 In the second phase of the study the P-Is treated their patients with the Reciproc instruments $(\mathrm{R})$ 105 exclusively. Each of the two treatment phases lasted for 2-3 months.

106 The study was made in conformity with the Declaration of Helsinki and the Professional Code

107 for Physicians of the Medical Council of the State of Baden-Württemberg. The P-Is informed 108 every potential participant personally about the purpose and extent of the study and about the 109 data protection aspects (pseudomization of data, destruction of the data at the moment of 110 withdrawal from the study). Before the patients were enrolled, they had to submit signed 111 informed consent to the study and to data storage. The Institutional Review Board of the Baden112 Württemberg Medical Council reviewed the study and approved it (AZ: F-2011-081-z).

\section{Patient eligibility and recruitment}

114 The structural similarity of the patients in the two phases was enhanced by inclusion and 115 exclusion criteria. The following criteria were defined for patients' enrollment in the study: The 116 patient had to be at least 18 years old and in need of initial orthograde root canal treatment of one 117 tooth. The exclusion criteria were: Hopeless teeth for periodontal or restorative reasons, patients 118 treated for pain only, dentitions in general need of rehabilitation, several symptomatic teeth 119 requiring endodontic treatment, other oral findings causing pain, craniomandibular dysfunction, 120 and communication difficulties.

\section{Practitioner Investigators (P-Is)}

122 The nine participating dentists were general dental practitioners without endodontic 123 specialization. They all used standard hand instruments for root canal therapy (RCT) and had no 124 routine experience with rotary mechanical instrument systems. In addition, none of them had 125 previously used single-file systems. All dentists followed the "Good Clinical Practice: Root 126 Canal Treatment" Guideline of DGZMK (German Society of Dental, Oral and Craniomandibular 127 Sciences) (Hülsmann \& Schäfer 2005) which is based on the Quality guidelines for endodontic 128 treatment of the Eupopean Society of Endodontology (2006) 


\section{Endodontic treatment protocol}

130 The endodontic access cavity was prepared under local anesthesia. Then the tooth was isolated

131 with a rubberdam. In the first phase of the study, depending on the situation, the root canals were 132 explored with stainless steel K-files of ISO sizes 06, 08, 10 and 15, in order to create a glidepath

133 up to ISO 15. Subsequently the root canals were fully prepared with stainless steel K-files by the 134 balanced-force technique when hand instrumentation was used (Roane et al. 1985). The working 135 length was determined electrometrically and/or by X-ray. In the second phase of the study the 136 root canals were prepared by means of the Reciproc instruments according to the manufacturer's 137 detailed instructions for use (Yared 2011). Glidepath preparation was not performed and the 138 canal was immediately instrumented with a Reciproc instrument. In all cases the Reciproc Gold 139 Motor was used for root canal preparation. If the P-I considered it necessary, he prepared the 140 glidepath. If the dentists wanted a final preparation size that is not included in the Reciproc 141 System, the ISO size was followed up by a single hand instrument of the ISO size 35 or 40 . After 142 preparation, root canals were irrigated with $\mathrm{NaOCl} \mathrm{1-3 \%} \mathrm{and} \mathrm{a} \mathrm{calcium} \mathrm{hydroxide} \mathrm{dressing} \mathrm{was}$ 143 placed in the root canals or the root canals were filled definitely. In case of a calcium hydroxide 144 dressing the tooth was provisionally sealed with a bacteria-proof filling. The treatment was 145 completed in a subsequent appointment either by root filling or in case that the root canal filling 146 was done in an earlier session, by placing a coronal bacteria-proof definite filling.

Measuring the reduction of patients' pain and $O H R Q O L$

148
The endodontic related pain and OHRQoL was measured by a patient questionnaire. Pain was evaluated by the Visual Analog Scale (VAS 100) (Turk 2011) and OHRQoL by the German short version of the oral health impact profile (OHIP-G-14) (John et al. 2004) which is the German translation of OHIP-14 (Slade 1997). The patients were asked about the biggest complaints in the week before treatment and in the week before completion of treatment. This was 14 days after initial treatment and in connection with either the placement of the root canal filling or the coronal filling of the tooth. Questionnaires were filled in by the patients before the treatment session started or while the local anesthesia was taking effect.

Assessment of patients' experience during treatment 
157 At completion of treatment the P-I asked four closed questions in a five-stage ordinal scale and

158 one open question about how the patients had experienced the treatment. They asked if the

159 patient was stressed / relaxed during treatment, if the anesthesia was sufficiently deep, if the

160 duration of treatment and the required wide mouth opening had put the patient under stress. The

161 answers covered five categories from completely true to not true at all. One open question was

162 about the most uncomfortable experience patients had during treatment.

163

164

165

166

167

168

169

170

171

172

173

174

175

176

177

178

179

180

181

182

183

\section{Assessment of dentist-related physical parameters during treatment}

In order to evaluate the physical strain during root canal preparation, after treatment the P-Is answered two closed questions in a five-stage ordinal scale from "completely true" to "not true at all”. The P-Is were asked if their general physical strain during root canal treatment was high and if after treatment they experienced the strain on their fingers. In addition, they were asked if the treatment was performed without glidepath preparation. The number of required therapy appointments was also recorded.

\section{Statistics}

The results were analyzed with the SPSS (Version 21, Win x64) statistics system.

\section{Results}

Six of the nine participating P-Is presented results suitable for evaluation. The remaining three PIs were excluded from evaluation. In all three cases the P-Is could not cope with the organizational demands and the resulting recruitment problems.

In the present study six P-Is performed and completed 137 endodontic treatments (Table 1). The P-Is treated 66 cases $(48.2 \%)$ in the first trial phase with hand instruments and 71 cases $(51.8 \%)$ in the second trial phase with Reciproc instruments. 62 (45.9\%) patients were women and 73 $(54.1 \%)$ were men. The gender distribution did not significantly differ in the two trial phases (Fisher's exact test $\mathrm{p}=0.301$ ). The P-Is treated between 5 and 20 cases per study group (Table 1). The distribution of the treatment cases to the P-Is and the study groups was not statistically different $\left(\chi^{2} 2.14\right.$ with $\left.5 \mathrm{DF}, \mathrm{p}=0.830\right)$. The average age of the participants was 52.1 (SD 16.33) years and did not differ in both study phases 52.1 (SD 16.4) vs. 52.0 (SD 16.4). 
184 The return rate of the different questionnaires that were completed by the patients and the P-Is 185 was $95.8 \%$ for the patients' follow-up pain questionnaire and $100 \%$ for the P-Is' questionnaires.

186 The return rate of the patients' pain questionnaire before treatment was $97.8 \%$ and for the

187 demographic data questionnaire it was 98.5\%. In all dental practices some patients did not

188 participate in the study. Their number and characteristics could not be collected. However, it is 189 unlikely that this drop-out in the two study phases was structurally different.

190

191

192

193

194 195

196

197

198

199

200

201

202

203

204

205

206

207

208

209

210

211

\section{Evaluating the reduction of patients' complaints}

For the evaluation of the primary outcome criterion, we measured pain reduction by VAS (100) and the improvement of OHRQoL (OHIP-G14 score), each being measured before root canal treatment and before completion of treatment, and compared the two study groups (Table 2).

The mean pain score before root canal treatment with hand instruments (H) was 43.6 (SD 30.7) VAS and with Reciproc (R) it was 41.2 (SD 27.7) VAS and decreased to 9.5 (SD 16.5) VAS (H) and 11.5 (SD 18.5) VAS (R).

The mean OHIP-G-14 score before root canal treatment with $(\mathrm{H})$ was 9.2 (SD 9.6) and with (R) it was 10.4 (SD 9.6) and decreased to 3.4 (SD 5.4) (H) and 3.5 (SD 6.1) (R).

For pain reduction and OHRQoL univariate analysis methods (ANOVA) showed a very similar improvement in both study groups $\mathrm{H}$ and $\mathrm{R}$ (Table 2). The difference in mean values before and after treatment with respect to the initial standard deviation is in pain greater than in OHRQoL. There was no statistically significant difference between the treatment methods regarding pain reduction and improvement of OHRQoL. A further multi-factor analysis of variance (MANOVA) with the additional factor "single vs. multiple-visit" treatment did not reveal any significant influence of the factors "study group (H and R)", "single vs. multiple-visit" or an interaction between the two factors regarding pain reduction and improvement of OHRQoL (all $\mathrm{p}>0.250)$.

\section{Evaluating patients' experience during treatment}

Most patients did not experience the root canal therapy as uncomfortable, regardless of the method used. Most patients were rather relaxed during treatment, considered the depth of anesthesia to be adequate and felt no great stress due to wide mouth opening (Figure 1). The two 
212 methods of root canal preparation did not differ in any of the three questions. In terms of

213 duration of treatment, however, the patients experienced the treatment with Reciproc as

214 significantly less stressful (Mann-Whitney-U Test $\mathrm{p}=0.018$ ).

215 The most frequent answer to the open question of what patients felt to be most uncomfortable

216 during treatment was "nothing" in both study groups. In the ranking of answers given, more

217 patients said that the root canal preparation itself was more uncomfortable with Reciproc,

218 whereas few patients said this about hand instrumentation. In addition, some patients considered

219 the rubber dam uncomfortable (Figure 2).

Assessment of dentist-related physical parameters during treatment

221 The P-Is were significantly less strained with the Reciproc System than with hand

222 instrumentation concerning both general physical strain and the strain on their fingers (Mann-

223 Whitney-U Test $\mathrm{p}=0.013$ and $\mathrm{p}<0.001$ ) (Figure 3).

224 Moreover, the P-Is treated significantly more root canals without glidepath preparation when

225 they used the Reciproc System (67.6\%) than they did with hand instruments $(22.7 \%)\left(\chi^{2} 27.7\right.$

226 with $1 \mathrm{DF}, \mathrm{p}<0.001)$.

\section{Number of therapeutic appointments}

228 Basically the number of therapeutic appointments did not differ between the systems. Two P-Is, 229 however, treated their patients in three appointments as a matter of principle. If these are 230 excluded from the evaluation, the number of appointments tends to decline with Reciproc

231 (Mann-Whitney-U Test $\mathrm{p}=0.035)$. With hand instrumentation 34 cases were completely prepared 232 in one appointment, 12 in two appointments and 1 in three appointments, whereas with Reciproc 23342 cases were prepared in one appointment, 5 in two and none in three appointments.

\section{Discussion}

235 Hand instrumentation as well as Reciproc preparation of root canals effectively reduced

236 endodontic related pain and OHRQoL. As the preparation with Reciproc has more advantages in

237 terms of patient comfort and dentist comfort, Reciproc is the technique to be preferred in this

238 respect. 
239

240

241

242

243

244

245

246

247

248

249

250

251

252

253

254

255

256

257

258

259

260

261

262

263

264

265

266

267

268

\section{Measuring the reduction of patients' discomfort}

The discomfort indicating the need for endodontic treatment was measured in our study by a combination of the Visual Analog Scale for pain and OHIP-G-14. Thus, the evaluation of the therapeutic procedures is based on measuring pain and the oral-health-related quality of life. The VAS is simple and has good evidence of construct validity (Turk 2011). It is widely referred to in the endodontic literature (King et al. 2012; Martin-Gonzalez et al. 2012; Pak 2012; Udoye \& Jafarzadeh 2011). The large number of scores (100) makes VAS more sensitive to changes in the intensity of pain felt as compared to scales with fewer answer categories (Turk 2011). Besides pain felt, the quality of life is an important patient-related outcome (Pfaff et al. 2011). The only validated measuring instrument for oral-health-related quality of life in German language is OHIP-G (John et al. 2003). To limit the questionnaire to a length that can still be handled, we used OHIP-G-14 in our study (John et al. 2004). At the time when our trial was planned in 2011, OHIP was used rarely for endodontic studies (Dugas et al. 2002; Gatten et al. 2011).

Results

In the present study, we compared two basically different methods of root canal preparation. In the first study phase the P-Is performed the endodontic therapy in their dental offices as usual with hand instruments. After training for the use of the Reciproc instruments, the P-Is prepared the root canals with the new system in the second phase of the study.

The introduction of new methods of treatment always raises the question about their benefit. The new system should have the same or better clinical results than the previous ones and offer an additional benefit at the same time. We defined the reduction of endodontic related discomfort, i.e. reduction of pain and improvement of oral-health-related quality of life, as the most important short-term patient-relevant outcome.

In pain assessment we found a reduction of the mean pain intensities before treatment by 44.6 $(\mathrm{H})$ and 41.2(R) VAS 100 to $9.5(\mathrm{H})$ and $11.5(\mathrm{R})$ with rather high standard deviations. This agrees quite well with other studies that reported pain reduction after endodontic therapy (Ehrmann et al. 2003; Pak 2012). The pain measurements made by Ehrmann et al. resulted in mean levels of 44.4 VAS (SD 26.9) before therapy and declined to 7.5 (SD 15.5) VAS (Ehrmann et al. 2003). The mean pain reduction of 36.9 (SD 29.0) was very similar to the levels we found in our study. Pak and White in their review also reported that pain intensity decreased from a 
269 mean level of 54 (SD 24) before therapy to levels below 10 VAS in the course of one week (Pak

270 \& White 2011).

271 The oral-health-related quality of life improved in our trial from mean OHIP-G-14-scores of 9.2

$272(\mathrm{H})$ and $10.4(\mathrm{R})$ to $3.4(\mathrm{H})$ and $3.5(\mathrm{R})$. Liu et al. in their study found mean OHIP-14-scores of

27315.4 (SD 10.5) before endodontic therapy (Liu et al. 2014). These scores are somewhat higher

274 and difficult to interpret because so far few studies have investigated the correlation between

275 endodontic related pain and oral-health-related quality of life.

276 In general, the endodontic literature proves that pain is reduced by endodontic therapy (Ehrmann

277 et al. 2003; Genet et al. 1986; Pak \& White 2011). However, comparative studies have so far

278 been dealing mainly with different pain medications (Attar et al. 2008), different dressings

279 (Ehrmann et al. 2003), effects of analgesia (Ryan et al. 2008) and the difference between single-

280 visit vs. multiple-visit treatments (Prashanth et al. 2011). Regarding single- versus multiple-visit

281 treatment no differences were found for one week postoperative pain levels (Figini et al. 2008;

282 Prashanth et al. 2011). This agrees with our observations, as we did not find statistically

283 significant differences in the MANOVA for single- versus multiple-visit treatments.

284 There are very few clinical studies, made with low case numbers ( $\mathrm{N}=30$ per experimental group),

285 that have investigated pain after root canal preparation with different instrumentation techniques

286 (Gambarini et al. 2013). In a recent randomized controlled trial no differences were found in

287 postoperative pain after preparation of root canals with different rotary or reciprocating canal

288 preparation systems (Kherlakian et al. 2016), which agrees with our results.

289 As the main outcome parameter of our study is the post treatment pain reduction, general

290 features of the used instruments ( $\mathrm{H}$ and $\mathrm{R}$ ) have to be considered regarding their influence to post

291 treatment pain. All endodontic instruments produce apically extruded debris (Al-Omari \&

292 Dummer 1995; Ghivari et al. 2011; Reddy \& Hicks 1998) that could lead to an irritation of the

293 periodontal ligament triggering a neurogenic inflammation response (Caviedes-Bucheli et al.

294 2013) that could lead to postoperative symptomatic apical periodontitis. Filing motion techniques

295 with hand preparation tend to extrude more debris beyond the apex than rotating motion

296 techniques with hand instruments (Al-Omari \& Dummer 1995) and rotary NiTi preparation

297 techniques (Reddy \& Hicks 1998). A recent review concludes, that reciprocating as well as 
298 rotary-file systems produce apical extrusion of debris and expression of neuropeptides in the 299 periodontal ligament (Caviedes-Bucheli et al. 2016), and that the inflammatory reaction is 300 influenced by the type of movement and file design of the instruments. Reciproc instruments 301 work in an asymmetrical reciprocating movement with a counterclockwise cutting action and a 302 following clockwise releasing motion. In combination with a S-shaped cross-sectional design 303 with relatively much space for debris, helicoidal angles and an instrument tip these instruments 304 are designed to avoid extrusion of debris beyond the apex and remove material out of the root 305 canal effectively (Caviedes-Bucheli et al. 2013). Consequently, Reciproc instruments showed 306 only slightly more expression of inflammatory peptides in the periodontal ligament after root 307 canal treatment than baseline teeth without instrumentation, while hand instrumentation in a filing motion showed the highest rates of expression (Caviedes-Bucheli et al. 2013). These results must be carefully interpreted in connection with our study because the direct correlation between expressed inflammatory peptides and the perceived pain cannot be exactly quantified by now. Theoretically hand instruments should have a higher tendency to postoperative pain compared to Reciproc instruments, but we found no differences in postoperative pain regardless of the instruments used. Perhaps this can be explained by the fact, that in our study hand instruments were used in a rotating motion.

In our trial most patients did not consider the endodontic treatment uncomfortable. But a significantly lower number of patients felt stressed by the duration of treatment when Reciproc was used as compared to hand instruments. We interpret this to be the result of the shorter time required for canal preparation which has already been shown in in-vitro comparisons with multiple-file rotary preparation systems (Bürklein et al. 2012). However, more patients felt the root canal preparation itself with Reciproc to be more uncomfortable than the preparation with hand instruments. We assume that this is due to the typical cracking sounds of the Reciproc instruments during root canal preparation.

The P-Is considered root canal preparation with the Reciproc System significantly less stressful in terms of general physical burden and strain on their fingers than hand preparation. There are few studies dealing with the physical strain on the dentist during root canal preparation. Onety et al. found that the muscle groups used in manual root canal preparation differ from those used in mechanical preparation (Onety et al. 2014). The study was made in a simulated treatment 
328 situation and does not contain any information about the strain the dentists themselves felt when

329 using the different methods. In general, they are under great physical strain during RCT which is 330 demonstrated by the large number of musculoskeletal disorders among endodontists (Zarra \&

331 Lambrianidis 2014).

332 The Reciproc System has been designed by the manufacturer for root canal preparation without a 333 glidepath. In our trial the P-Is were able to prepare the root canals without glidepath preparation 334 in the great majority of cases $(67,6 \%)$. De-Deus et al. in their in-vitro study found that $93.4 \%$ of 335 the root canals could be prepared without glidepath preparation (De-Deus et al. 2013). We 336 believe that the lower rate in our study is due to the fact that the P-Is had no experience in either 337 rotary or Reciproc canal preparation before the trial. Since the system was implemented by the P338 Is without the chance of going through a learning curve, we think the rate obtained is very good.

339 In our trial the number of appointments required for root canal treatment tended to go down. As 340 far as the authors know, no study has so far been made on the influence of the preparation 341 methods on the number of therapeutic appointments. In general, the treatment result hardly 342 shows whether an endodontic therapy was performed as single-visit or multiple-visit procedure 343 (Prashanth et al. 2011; Su et al. 2011). A reduction of the required number of appointments is a 344 desirable outcome regarding patient comfort, but does not necessarily reflect long-term 345 biological objectives.

346 Hand instrumentation and Reciproc preparation effectively reduce endodontic related discomfort.

347 Reciproc, however, has advantages in terms of how the patients feel during treatment and with 348 regard to the physical strain on the dentist. For the patients the duration of treatment with 349 Reciproc is less stressful and the number of appointments tends to be lower. The dentists 350 consider Reciproc to be significantly less physically stressful than hand instrumentation.

\section{Acknowledgements}

352 VDW made Reciproc Gold Motors and Reciproc files available free of cost for the purpose of 353 the trial. There is no conflict of interest between the authors and VDW. 
354

355

356

357

358

359

360

361

362

363

364

365

366

367

368

369

370

371

372

373

374

375

376

377

378

379

380

381

382

\section{References}

2006. Quality guidelines for endodontic treatment: consensus report of the European Society of Endodontology. Int Endod J 39:921-930.

Al-Omari MA, and Dummer PM. 1995. Canal blockage and debris extrusion with eight preparation techniques. $J$ Endod 21:154-158.

Attar S, Bowles WR, Baisden MK, Hodges JS, and McClanahan SB. 2008. Evaluation of pretreatment analgesia and endodontic treatment for postoperative endodontic pain. $J$ Endod 34:652-655. 10.1016/j.joen.2008.02.017

Bürklein S, Hinschitza K, Dammaschke T, and Schäfer E. 2012. Shaping ability and cleaning effectiveness of two single-file systems in severely curved root canals of extracted teeth: Reciproc and WaveOne versus Mtwo and ProTaper. International Endodontic Journal 45:449-461. 10.1111/j.1365-2591.2011.01996.x

Caviedes-Bucheli J, Castellanos F, Vasquez N, Ulate E, and Munoz HR. 2016. The influence of two reciprocating single-file and two rotary-file systems on the apical extrusion of debris and its biological relationship with symptomatic apical periodontitis. A systematic review and meta-analysis. International Endodontic Journal 49:255-270. 10.1111/iej.12452

Caviedes-Bucheli J, Moreno JO, Carreno CP, Delgado R, Garcia DJ, Solano J, Diaz E, and Munoz HR. 2013. The effect of single-file reciprocating systems on Substance P and Calcitonin gene-related peptide expression in human periodontal ligament. Int Endod $J$ 46:419-426. 10.1111/iej.12005

De-Deus G, Arruda TE, Souza EM, Neves A, Magalhaes K, Thuanne E, and Fidel RA. 2013. The ability of the Reciproc R25 instrument to reach the full root canal working length without a glide path. International Endodontic Journal. 10.1111/iej.12091

Dugas NN, Lawrence HP, Teplitsky P, and Friedman S. 2002. Quality of life and satisfaction outcomes of endodontic treatment. J Endod 28:819-827. 10.1097/00004770-20021200000007

Ehrmann EH, Messer HH, and Adams GG. 2003. The relationship of intracanal medicaments to postoperative pain in endodontics. International Endodontic Journal 36:868-875. 10.1111/j.1365-2591.2003.00735.x 
383 Figini L, Lodi G, Gorni F, and Gagliani M. 2008. Single versus multiple visits for endodontic

384

385

386

387

388

389

390

391

392

393

394

395

396

397

398

399

400

401

402

403

404

405

406

407

408

409

410

411

412

413 treatment of permanent teeth: a Cochrane systematic review. J Endod 34:1041-1047. 10.1016/j.joen.2008.06.009

Fleming CH, Litaker MS, Alley LW, and Eleazer PD. 2010. Comparison of classic endodontic techniques versus contemporary techniques on endodontic treatment success. $J$ Endod 36:414-418. 10.1016/j.joen.2009.11.013

Gambarini G, Testarelli L, De Luca M, Milana V, Plotino G, Grande NM, Rubini AG, Al Sudani D, and Sannino G. 2013. The influence of three different instrumentation techniques on the incidence of postoperative pain after endodontic treatment. Annali di stomatologia 4:152-155. 10.11138/ads.0152

Gatten DL, Riedy CA, Hong SK, Johnson JD, and Cohenca N. 2011. Quality of life of endodontically treated versus implant treated patients: a University-based qualitative research study. J Endod 37:903-909. 10.1016/j.joen.2011.03.026

Genet JM, Wesselink PR, and Thoden van Velzen SK. 1986. The incidence of preoperative and postoperative pain in endodontic therapy. Int Endod J 19:221-229.

Ghivari SB, Kubasad GC, Chandak MG, and Akarte N. 2011. Apical extrusion of debris and irrigant using hand and rotary systems: A comparative study. J Conserv Dent 14:187-190. 10.4103/0972-0707.82622

Hargreaves KM, Cohen S, and Berman LH. 2011. Cohen's pathways of the pulp. St. Louis, Mo.: Mosby Elsevier.

Hülsmann M, and Schäfer E. 2005. "Good clinical practice": Die Wurzelbehandlung. Stellungnahme der DGZ/DGZMK. Deutsche Zahnärztliche Zeitschrift 60:418.

John M, Micheelis W, and Biffar R. 2004. Normwerte mundgesundheitsbezogener Lebensqualität für Kurzversionen des Oral Health Impact Profle. Schweiz Monatsschr Zahnmed 114:784-791.

John MT, LeResche L, Koepsell TD, Hujoel P, Miglioretti DL, and Micheelis W. 2003. Oral health-related quality of life in Germany. Eur J Oral Sci 111:483-491.

Kherlakian D, Cunha RS, Ehrhardt IC, Zuolo ML, Kishen A, and da Silveira Bueno CE. 2016. Comparison of the Incidence of Postoperative Pain after Using 2 Reciprocating Systems and a Continuous Rotary System: A Prospective Randomized Clinical Trial. J Endod 42:171-176. 10.1016/j.joen.2015.10.011 
414 King JW, Bair E, Duggan D, Maixner W, and Khan AA. 2012. The relationship between resting

415

416

417

418

419

420

421

422

423

424

425

426

427

428

429

430

431

432

433

434

435

436

437

438

439

440

441

442

443 arterial blood pressure and acute postoperative pain in endodontic patients. J Orofac Pain 26:321-327.

Kumar BS, Pattanshetty S, Prasad M, Soni S, Pattanshetty KS, and Prasad S. 2013. An in-vitro Evaluation of canal transportation and centering ability of two rotary Nickel Titanium systems (Twisted Files and Hyflex files) with conventional stainless Steel hand Kflexofiles by using Spiral Computed Tomography. J Int Oral Health 5:108-115.

Liu P, McGrath C, and Cheung G. 2014. What are the key endodontic factors associated with oral health-related quality of life? International Endodontic Journal 47:238-245. 10.1111/iej.12139

Martin-Gonzalez J, Echevarria-Perez M, Sanchez-Dominguez B, Tarilonte-Delgado ML, Castellanos-Cosano L, Lopez-Frias FJ, and Segura-Egea JJ. 2012. Influence of root canal instrumentation and obturation techniques on intra-operative pain during endodontic therapy. Med Oral Patol Oral Cir Bucal 17:e912-918.

Onety GC, Leonel DV, Saquy PC, Silva GP, Ferreira B, Varise TG, Sousa LG, Verri ED, Siessere S, Semprini M, Nepomuceno VR, and Regalo SC. 2014. Analysis of endodontist posture utilizing cinemetry, surface electromyography and ergonomic checklists. Braz Dent J 25:508-518. 10.1590/0103-6440201302438

Pak JG. 2012. Patient-Based Endodontic Outcomes, Systematic Reviews of Pathology and Pain Prevalences.

Pak JG, and White SN. 2011. Pain prevalence and severity before, during, and after root canal treatment: a systematic review. J Endod 37:429-438. 10.1016/j.joen.2010.12.016

10.1016/j.joen.2010.12.016.

Patsopoulos NA. 2011. A pragmatic view on pragmatic trials. Dialogues Clin Neurosci 13:217224.

Pfaff H, Nellessen-Martens G, and Scriba PC. 2011. Lehrbuch Versorgungsforschung Systematik - Methodik-Anwendung ; mit 19 Tabellen ; [input, throughput, output, outcome]. Stuttgart: Schattauer.

Prashanth MB, Tavane PN, Abraham S, and Chacko L. 2011. Comparative evaluation of pain, tenderness and swelling followed by radiographic evaluation of periapical changes at 
444

445

446

447

448

449

450

451

452

453

454

455

456

457

458

459

460

461

462

463

464

465

466

467

468

469

470

471

472

various intervals of time following single and multiple visit endodontic therapy: an in vivo study. J Contemp Dent Pract 12:187-191.

Reddy SA, and Hicks ML. 1998. Apical extrusion of debris using two hand and two rotary instrumentation techniques. J Endod 24:180-183. 10.1016/s0099-2399(98)80179-9

Roane JB, Sabala CL, and Duncanson MG, Jr. 1985. The "balanced force" concept for instrumentation of curved canals. J Endod 11:203-211. 10.1016/S0099-2399(85)80061-3

Ryan JL, Jureidini B, Hodges JS, Baisden M, Swift JQ, and Bowles WR. 2008. Gender differences in analgesia for endodontic pain. $J$ Endod 34:552-556. 10.1016/j.joen.2008.01.021

Schäfer E, and Florek H. 2003. Efficiency of rotary nickel-titanium K3 instruments compared with stainless steel hand K-Flexofile. Part 1. Shaping ability in simulated curved canals. Int Endod J 36:199-207.

Slade GD. 1997. Derivation and validation of a short-form oral health impact profile. Community Dent Oral Epidemiol 25:284-290.

Su Y, Wang C, and Ye L. 2011. Healing rate and post-obturation pain of single- versus multiplevisit endodontic treatment for infected root canals: a systematic review. J Endod 37:125132. 10.1016/j.joen.2010.09.005

Turk DC. 2011. Handbook of pain assessment. New York [u.a.]: Guilford Press.

Udoye CI, and Jafarzadeh H. 2011. Pain during root canal treatment: an investigation of patient modifying factors. $J$ Contemp Dent Pract 12:301-304.

Yared G. 2008. Canal preparation using only one Ni-Ti rotary instrument: preliminary observations. Int Endod J 41:339-344. IEJ1351 [pii]

10.1111/j.1365-2591.2007.01351.x

Yared G. 2011. Canal preparation with only one reciprocating instrument without prior hand filing: A new concept. Available at http://www.vdwdental.com/fileadmin/redaktion/downloads/presse/yared_reciproc_concept_en.pdf.

Zarra T, and Lambrianidis T. 2014. Musculoskeletal disorders amongst Greek endodontists: a national questionnaire survey. Int Endod J 47:791-801. 10.1111/iej.12219 


\section{Tables}

474 Table 1. Number of patients treated with the different systems by practitioner-investigators

\begin{tabular}{|c|c|c|c|}
\hline$\overline{\text { P-I ID }}$ & Studygroup & & Total (N) \\
\hline & $\begin{array}{l}\text { Hand pre- } \\
\text { paration }(\mathrm{N})\end{array}$ & Reciproc (N) & \\
\hline 1 & 9 & 12 & 21 \\
\hline 2 & 10 & 12 & 22 \\
\hline 3 & 20 & 14 & 34 \\
\hline$<$ & 8 & 9 & 17 \\
\hline 5 & 14 & 18 & 32 \\
\hline 6 & 5 & 6 & 11 \\
\hline Total (N) & 66 & 71 & 137 \\
\hline
\end{tabular}

476 
477 Table 2. Comparison of pain and oral health related quality of life (OHRQoL) by study group 478 (ANOVA)

\begin{tabular}{|c|c|c|c|}
\hline & $\begin{array}{l}\text { Hand } \\
\text { preparation } \\
\text { mean (SD) }\end{array}$ & $\begin{array}{l}\text { Reciproc } \\
\text { mean (SD) }\end{array}$ & Sign. \\
\hline Pain before treatment (VAS 100) & $43.6(\mathrm{SD} 30.7)$ & $41.2(\mathrm{SD} 27.7)$ & (n.s.) \\
\hline Pain before end of treatment & $9.5(\mathrm{SD} 16.5)$ & $11.5(\mathrm{SD} 18.5)$ & (n.s.) \\
\hline Pain reduction (VAS 100) & $32.6(\mathrm{SD} 32.9)$ & $29.4(\mathrm{SD} 26.9)$ & $\begin{array}{c}\mathrm{p}=0.550 \\
\text { (n.s.) }\end{array}$ \\
\hline (Pain reduction) $/(\mathrm{SD}$ before treatment) & 1.06 & 1.06 & \\
\hline OHIP-G-14 Score before treatment & $9.2(\mathrm{SD} 9.6)$ & $10.4(\mathrm{SD} 9.6)$ & (n.s.) \\
\hline $\begin{array}{l}\text { OHIP-G-14 Score before end of } \\
\text { treatment }\end{array}$ & $3.4(\mathrm{SD} 5.4)$ & $3.5(\mathrm{SD} 6.1)$ & (n.s.) \\
\hline $\begin{array}{l}\text { Improvement of OHRQoL (OHIP- } \\
\text { G14) }\end{array}$ & $5.5(\mathrm{SD} 9.2)$ & $6.7(\mathrm{SD} 7.4)$ & $\begin{array}{c}\mathrm{p}=0.383 \\
\text { (n.s.) }\end{array}$ \\
\hline $\begin{array}{l}\text { (Improvement OHIP-G-14)/(SD before } \\
\text { treatment) }\end{array}$ & 0.57 & 0.70 & \\
\hline
\end{tabular}

479

480

481

482

483

484

485 
488 Figures

489

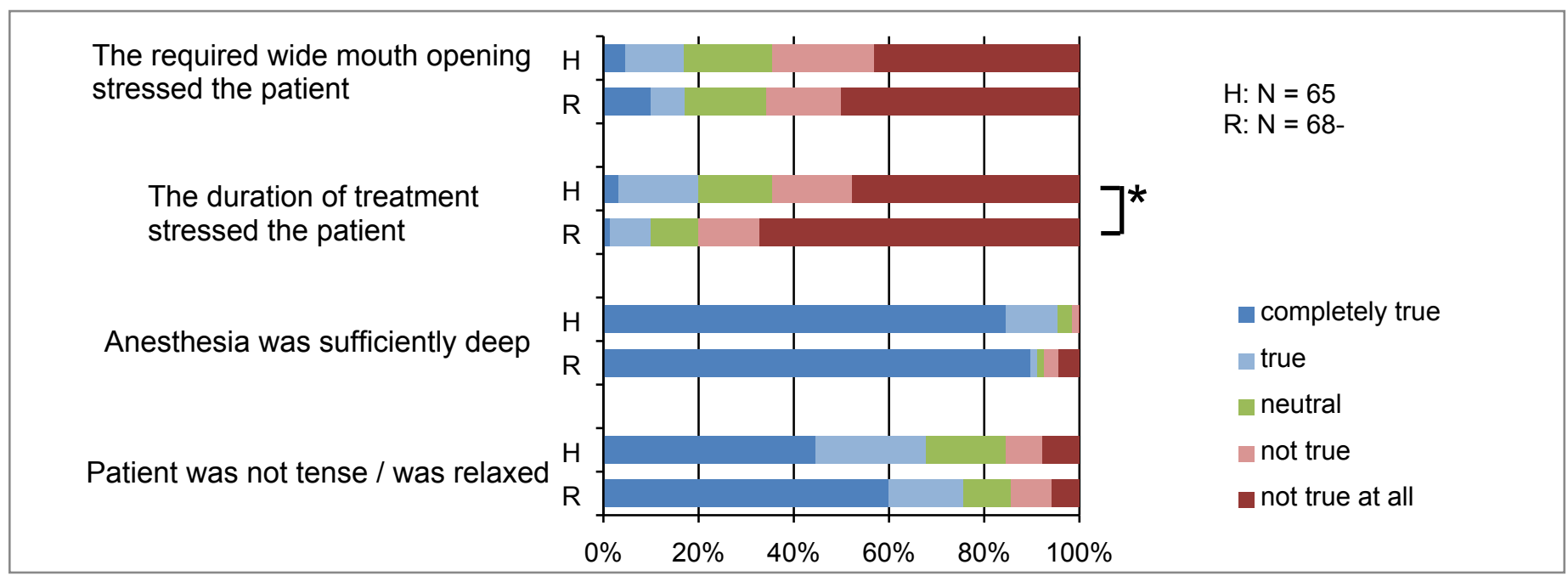

490 Figure 1. Patients' feelings during treatment in treatment groups. In the Reciproc group (R)

491 patients felt significantly less stress during treatment than in the hand preparation group $(\mathrm{H})$

492 (*Mann-Whitney-U Test $\mathrm{p}=0.018$ ). 


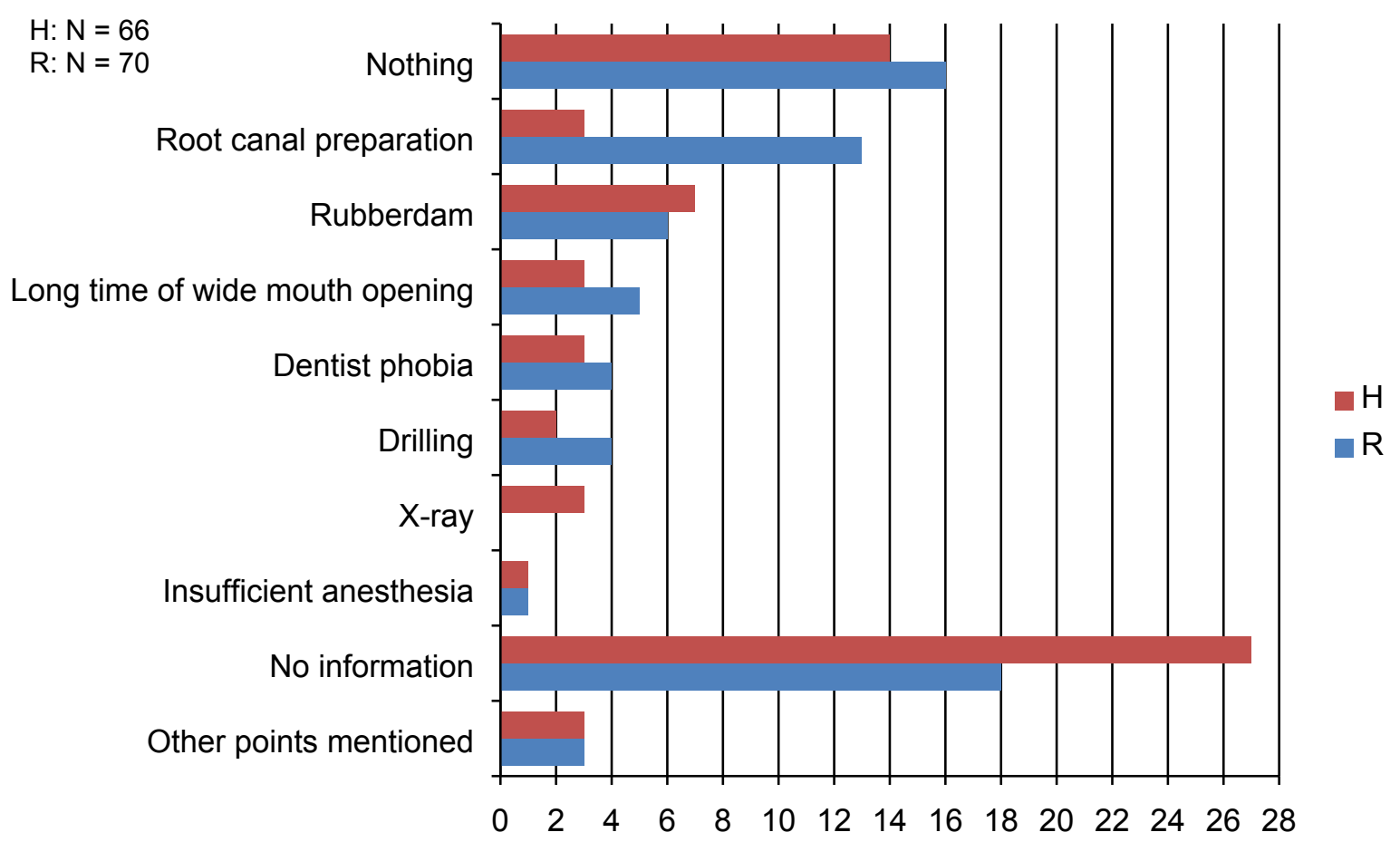

Figure 2. Patients' answers to the open question what was most uncomfortable during treatment 495 (Number of answers (N)) 
496

497 498 physical and finger strain than in the hand preparation group $(\mathrm{H})(\mathrm{Mann}-\mathrm{Whitney-U}$ Test $499 \mathrm{p}=0.013$ and $\mathrm{p}<0.001)$. In the Reciproc group glidepath preparation was significantly less often 500 required (Mann-Whitney-U Test $\mathrm{p}<0.001)$. (* Difference between the groups $\mathrm{p}<0.05)$

In general I felt great physical strain during root canal preparation

After treatment I could feel the strain on my fingers
$\left.\begin{array}{l}H \\ R\end{array}\right]$

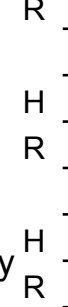

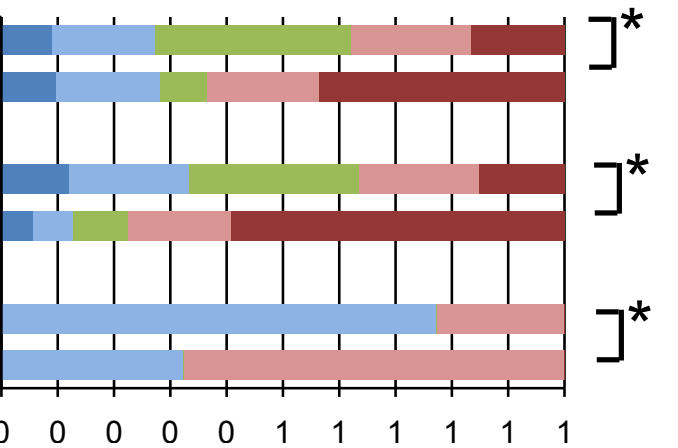

$\mathrm{H}: \mathrm{N}=66$ R: $N=71$

completely true true neutral not true not true at all Figure 3. Physical strain on dentists. In the Reciproc group (R) the P-Is felt significantly less 